IOS Press

\title{
Review
}

\section{Tip of the Iceberg: Assessing the Global Socioeconomic Costs of Alzheimer's Disease and Related Dementias and Strategic Implications for Stakeholders}

\author{
Youssef H. El-Hayek ${ }^{\mathrm{a}}$, Ryan E. Wiley ${ }^{\mathrm{a}, \mathrm{b}}$, Charles P. Khoury ${ }^{\mathrm{a}}$, Ritesh P. Daya ${ }^{\mathrm{a}}$, Clive Ballard $^{\mathrm{c}}$, \\ Alison R. Evans ${ }^{\mathrm{d}}$, Michael Karran ${ }^{\mathrm{d}}$, José Luis Molinuevo ${ }^{\mathrm{e}, \mathrm{f}}$, Matthew Norton ${ }^{\mathrm{d}}$ and Alireza Atri ${ }^{\mathrm{g}, \mathrm{h}, *}$ \\ ${ }^{\text {a }}$ Shift Health, Toronto, ON, Canada \\ ${ }^{\mathrm{b}}$ Department of Pathology and Molecular Medicine, McMaster University, Hamilton, ON, Canada \\ ${ }^{\mathrm{c}}$ University of Exeter, Exeter, $U K$ \\ 'Alzheimer's Research UK, Cambridge, UK \\ ${ }^{\mathrm{e}}$ Barcelonaßeta Brain Research Center, Barcelona, Spain \\ ${ }^{\mathrm{f}}$ Paqual Maragall Foundation, Barcelona, Spain \\ ${ }^{\mathrm{g}}$ Banner Sun Health Research Institute, Banner Health, Sun City, AZ, USA \\ ${ }^{\mathrm{h}}$ Department of Neurology, Center for Brain/Mind Medicine, Brigham and Women's Hospital, \\ Harvard Medical School, Boston, MA, USA
}

Accepted 10 May 2019

\begin{abstract}
While it is generally understood that Alzheimer's disease (AD) and related dementias (ADRD) is one of the costliest diseases to society, there is widespread concern that researchers and policymakers are not comprehensively capturing and describing the full scope and magnitude of the socioeconomic burden of ADRD. This review aimed to 1) catalogue the different types of AD-related socioeconomic costs described in the literature; 2) assess the challenges and gaps of existing approaches to measuring these costs; and 3) analyze and discuss the implications for stakeholders including policymakers, healthcare systems, associations, advocacy groups, clinicians, and researchers looking to improve the ability to generate reliable data that can guide evidence-based decision making. A centrally emergent theme from this review is that it is challenging to gauge the true value of policies, programs, or interventions in the ADRD arena given the long-term, progressive nature of the disease, its insidious socioeconomic impact beyond the patient and the formal healthcare system, and the complexities and current deficiencies (in measures and real-world data) in accurately calculating the full costs to society. There is therefore an urgent need for all stakeholders to establish a common understanding of the challenges in evaluating the full cost of ADRD and define approaches that allow us to measure these costs more accurately, with a view to prioritizing evidence-based solutions to mitigate this looming public health crisis.
\end{abstract}

Keywords: Alzheimer's disease, caregivers, cost of illness, dementia, disease progression, health care costs, health policy, long-term care, resource allocation

${ }^{*}$ Correspondence to: Alireza Atri, MD, PhD, Director, Banner Sun Health Research Institute, 10515 W Santa Fe Drive, Sun City, AZ 85351, USA. Tel.: +1 623832 5466; Fax: +1 623832 5461; E-mail: alireza.atri@bannerhealth.com.

\section{INTRODUCTION}

Alzheimer's disease (AD) and related dementias (ADRD) are a major cause of disability and depen- 
dency among older adults worldwide [1], having a significant impact not only on individuals but also on their families, communities, and societies. In 2015 , dementia costs were estimated at US\$818 billion, equivalent to $1.1 \%$ of global gross domestic product-a staggering cost that had grown by $35 \%$ since 2010. By 2030, it is estimated that the global cost of dementia could grow to US $\$ 2$ trillion, which could overwhelm health and social care systems [2].

While it is generally acknowledged that ADRD is one of the costliest diseases to society [3, 4], the burden is complex and has been difficult to assess accurately due to myriad factors $[2,4,5]$. As patients require the support of multiple stakeholders across the healthcare and social care sectors, as well as from family members and friends, the cost of care is not neatly captured by typical healthcare delivery systems. The impact on the quality of life of both patients and their caregivers [6] is not readily translated into monetary costs. While our understanding of the mechanisms of $\mathrm{AD}$ and related neurodegenerative diseases, co-morbidities, and aging processes, that often combine to lead to cognitive or behavioral decline, clinical symptoms and cognitive impairment and dementia (CID), is expanding, it still remains limited [7]. This limited understanding, combined with the practical challenges that result in low rates of detection, diagnosis, disclosure, and care [7] in patients with ADRD until the middle and later stages of CID, results in a potentially significant, but grievously understudied, 'hidden' cost associated with early ADRD. Moreover, considerable heterogeneity exists across cost of illness studies with respect to the nature of the populations studied, terminologies and the methods used $[5,8-11]$.

Concerns have recently been raised that researchers and policymakers are not comprehensively capturing and describing the full scope and magnitude of the socioeconomic burden of ADRD and that additional research is needed to better capture the value of care and costs of ADRD $[5,6]$. In the U.S., there also appears to be significant gender and racial/ethnic disparities in prevalence, access, and costs related to CID, with costs and care burden being much higher in women and minorities, particularly Blacks/African American [6, 12]. From a public policy perspective, accurately assessing the socioeconomic costs of ADRD is critical to prioritizing effective, evidence-based policies, and intervention and implementation strategies, particularly given the potential arrival of high-cost interventions, such as disease-modifying therapies, whose cost-effectiveness may be difficult to ascertain by conventional methods. Several reports have recently discussed the challenges and limitations in assessing the full costs of ADRD, with varying degrees of scope and comprehensiveness [5, 13, 14].

This review aimed to 1) catalogue the different types of ADRD-related socioeconomic costs described in the literature; 2) assess the challenges and gaps of existing approaches to measuring these costs; and, 3) analyze and discuss the implications for stakeholders including policymakers, healthcare systems, associations, advocacy groups, clinicians and researchers looking to improve our ability to generate reliable data that can guide evidence-based decision making.

\section{DEFINITIONS}

Please see Table 1 for a glossary of abbreviations used in this review. As many of the reports cited in this review did not explicitly separate individuals with $\mathrm{AD}$ from patients with other causes of CID (e.g., vascular cognitive impairment and dementia, dementia with Lewy bodies, frontotemporal dementias), and with the recognition that the sporadic AD phenotype in older individuals is often due to mixed pathologies that include $\mathrm{AD}$ (e.g., $\mathrm{AD}+$ vascular-ischemic brain injury pathologies; AD+Lewy body pathologies) [15-18] the term 'Alzheimer's and related dementias (ADRD)', as employed in other reviews, was used when presenting and discussing the costs of diseases [14]. The terms 'Alzheimer's' or 'AD' were used when the data or discussion is relevant only to $\mathrm{AD}$; for example, when discussing diagnostic criteria and biomarkers [19].

Table 1

Glossary of abbreviations

Alzheimer's Disease (AD)

Alzheimer's Disease and Related Dementias (ADRD)

Cognitive Impairment and Dementia (CID)

Dementia Quality of Life (DEMQOL)

Emergency Department (ED)

EuroQol Five-Dimension Questionnaire (EQ-5D)

Health-Related Quality of Life (HRQOL)

Mild Cognitive Impairment (MCI)

Out of Pocket (OOP)

Quality of Life (QOL)

Quality of Life in Alzheimer's Disease (QOL-AD)

Quality-Adjusted Life Year (QALY)

Resource Utilization in Dementia (RUD)

Zarit Burden Interview (ZBI) 


\section{DIRECT COSTS}

Direct costs have been described as goods and services for which money is explicitly exchanged [20]. In the context of ADRD, this is generally considered to include medical and social/non-medical care costs for patients related to their illness $[8$, 21-28]. While the classification of medical and social care costs can vary across countries, direct medical costs typically include elements such as medical practitioner/allied health professional visits, hospital care, medical treatments/medications, and specialized aids and equipment. Social care and non-medical costs could include elements such as community and social services (e.g., transportation, peer support, and psychosocial interventions), private and publicly funded home care, special accommodations (e.g., nursing homes), patient income and welfare support, and household expenses (e.g., home modifications). While it is recognized that caregivers can exhibit an array of health issues (e.g., depression, weakened immune system, and cardiovascular problems) associated with the stresses of caring for patients with ADRD [29-32], there is a lack of consensus in the literature on how to categorize the direct costs associated with caring for the caregiver. In this review, both patient- and caregiver-related costs for which money is explicitly exchanged are included under the category of "Direct Costs". Please see Box 1 for a summary of key findings from this section.

\section{Patients and caregivers: Measurement of direct costs}

Direct medical and social/non-medical costs have generally been measured using two approaches. Several studies have relied on administrative data drawn from centralized databases such as insurance claims data or patient registries [14]. Others have employed surveys or standardized questionnaires administered to patients and their caregivers to measure self-reported resource utilization for patients and caregivers (e.g., living accommodation, hospitalizations, community care services); healthcare costs are then estimated by multiplying unit costs of services and products by recorded resource use [33]. Several instruments have been used to gather resource use data, including Resource Utilization in Dementia (RUD), Client Service Receipt Inventory, Resource Use Inventory, cost diary, and informal care survey [33, 34]. The RUD, and its short version, the RUD Lite, are among the most, if not the most, commonly used instrument for collecting resource use data in

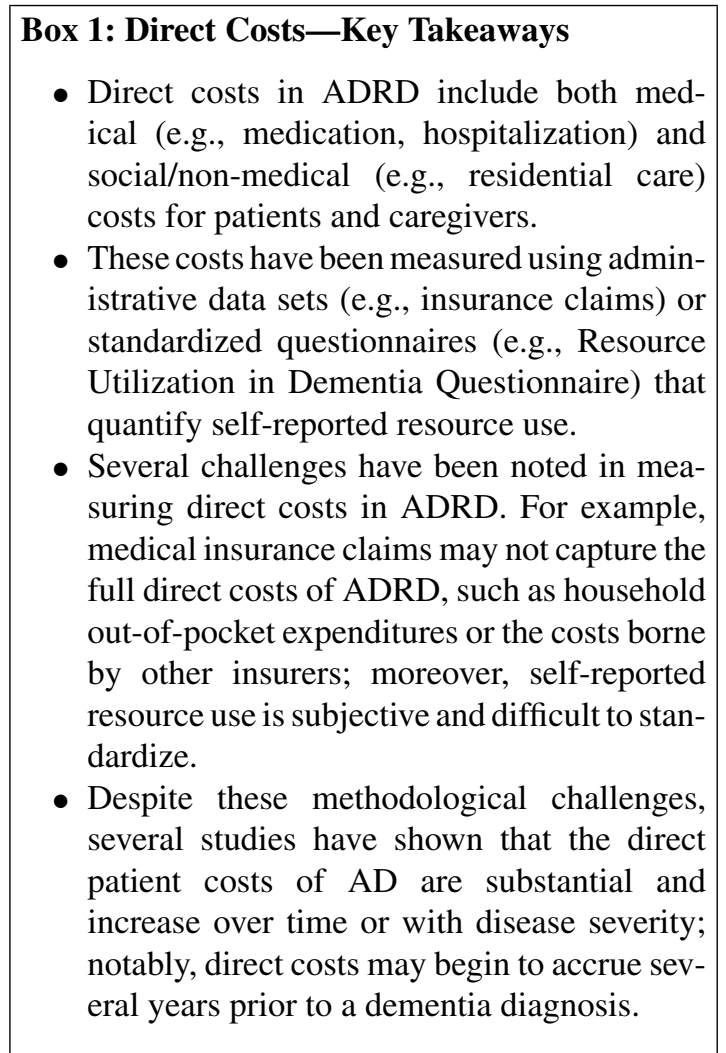

ADRD [34]. The RUD was designed, over 20 years ago, to be useful in different care settings, across different countries and care systems, and provides an informant-reported estimate of caregiving time and related activities; support services received by the patient (e.g., day care, meals on wheels, inhome care), medications, and medical/health-related visits (e.g., number of visits to general practitioner or physiotherapist, emergency department [ED] and hospitalizations). While numbers of visits to the ED and nights spent in hospital in different wards are reported by the informant and are counted in "units" of utilization to be multiplied by a generic (mean) unit costs per service, lack of verification of number, nature, and extent of each service utilized represents a major limitation in extrapolation of the actual costs incurred.

Several additional challenges have been noted in measuring direct costs in ADRD. In general, ADRD, particularly early in its course, has been under- or misdiagnosed or underreported [14], which could lead to the under- or overestimation of costs across studies [35-37]. Additionally, many studies have applied variable and specific inclusion criteria (e.g., availability of an informal caregiver, enrolled 
in memory clinics), which can potentially introduce selection bias and challenges the validity of extrapolating results to the general ADRD population $[25,26$, 38]. Moreover, most patients in the dementia stages of ADRD are elderly and typically suffer from comorbidities, such as cerebrovascular disease, albeit at a higher rate compared to individuals without ADRD [39, 40]. Most reports, however, do not distinguish direct costs that are a consequence of ADRD symptoms from direct costs attributable to comorbidities. Similarly, it has been challenging to ascribe caregiver direct costs as a specific and unique consequence of caregiving for an ADRD patient [25].

From a methodological standpoint, studies based on medical insurance claims data may not capture the full direct costs of ADRD, such as out-of-pocket expenses (e.g., co-payments) borne by patients and caregivers or the costs to other insurers (e.g., pension insurance paying for rehabilitation services) [14, 38]. While studies relying on surveys and questionnaires may capture a broader range of costs, these are based on self-reported measures and might be subject to inaccuracies $[14,26]$. For example, it has been shown that survey estimates tend to underestimate healthcare utilization in the elderly population [41], and this effect could be hypothesized to be even potentially greater due to impairments in awareness, insight, memory and cognition in individuals with ADRD.

\section{Commentary}

\section{Direct costs for patients begin to mount before a diagnosis of $A D R D$}

Using records from the Danish National Patient Registry, increased healthcare costs were identified in patients as early as 10 years prior to a diagnosis of ADRD [22]. Importantly, partners of patients exhibited statistically significant increases in healthcare costs up to 2 years prior to diagnosis. Similarly, other studies have found that healthcare costs increase in both ADRD [42-44] and mild cognitive impairment (MCI) [42] patients up to one-year prior to diagnosis [44]. For example, Medicare expenditures were $42 \%$ and $41 \%$ higher in ADRD and MCI patients, respectively, compared to matched controls one year prior to diagnosis. The propensity of evidence supports that individuals with undiagnosed ADRD account for higher direct costs in the years leading up to the ultimate recognition and diagnosis of their cognitive impairment/dementia. The driver of these costs relates to consequences of unrecognized or unmanaged cognitive and behavioral impairments and vulnerabilities in individuals with undiagnosed ADRD that could include: 1) exacerbation of co-morbid conditions due to the patient's inability to properly manage their medical conditions (that can lead to additional unnecessary testing, medications, procedures, ED visits and hospitalizations); 2) diagnostic testing, medications, or procedures for vague or unrecognized dementia-associated symptoms (e.g., depression, hearing loss, GI symptoms, dizziness, anxiety, and sleep disturbances); 3) injuries such as falls, motor vehicle accidents, and accidents in the home precipitated by lack of planning, foresight, insight, judgment, or cognitive abilities; and 4) delirium [45], a major driver for ED visits and hospitalizations, as well as in-hospital or post-operative complication and morbidity.

\section{Direct costs generally increase over time, driven primarily by social care costs}

Several longitudinal studies have shown that the direct patient costs of $\mathrm{AD}$ increase over time or with disease severity [24, 25, 27, 46] and are higher in nursing home residents, compared to communitydwelling patients [26, 47]. In community-dwelling patients, the main driver appears to be patient social care costs $[24,25]$, while direct medical costs for patients and for caregivers do not differ according to ADRD severity [24, 25, 46].

\section{Out-of-pocket expenditures borne by ADRD patients are high, exceed those of individuals without ADRD, and are disproportionately \\ borne by women and minorities}

Only a few studies, primarily based on US populations, have conducted detailed analyses of out-of-pocket expenditures in ADRD patients and caregivers and the subsequent burden placed on households and families [14]. For example, in a study of Medicare beneficiaries in the US, out-of-pocket (OOP) expenditures were higher in patients with ADRD. Moreover, another study of Medicare beneficiaries examined OOP spending during the last 5 years of life and found that OOP spending for patients with dementia represented $32 \%$ of household wealth compared to $11 \%$ for individuals without ADRD. Moreover, the proportion of spending was higher for African Americans, unmarried/widowed women, and those with less than high school education [48]. Similarly, out-of-pocket spending in caregivers of patients with ADRD is approximately twice as high as those for caregivers of individuals without ADRD [49]. 
The Alzheimer's Association has estimated that OOP costs in 2018 could reach US $\$ 60$ billion, or approximately $22 \%$ of the total costs of the disease [49].

\section{INDIRECT COSTS}

Indirect costs have generally been defined as a "resource lost or invested for which no money is exchanged" [20]. As noted by Alzheimer's Disease International $[9,50]$, there are two main sources of indirect costs in ADRD. These include the costs of informal care, arising from the unpaid inputs or the productivity losses of informal caregivers, such as families, friends, and others. In the U.S., it is estimated that annually 18.5 billion hours of informal care are provided by caregivers to individuals with ADRD that translates to a contribution valuation of US\$234 billion per year [6]. Indirect costs may also arise from productivity losses in patients due to work impairment, sick leave, early retirement, or mortality. The estimated total lifetime cost of providing care for an individual with dementia was US\$350,174 in 2018 dollars and the costs associated with family care make up $70 \%$ of lifetime dementia care costs $[6,51]$. Furthermore, these estimates likely underestimate the full impact of family caregivers' health and workplace productivity $[6,14]$. Please see Box 2 for a summary of key findings from this section.

\section{Caregivers: Informal care costs}

The impact of ADRD on informal caregiver productivity has been assessed through various approaches, including semi-quantitative surveys and structured questionnaires aimed at caregivers. For example, surveys conducted by Carers UK and Employers for Carers [52] and the Alzheimer's Association [53] have asked series of questions on employment challenges. In other studies, impairments have been assessed by quantifying employment absenteeism and presenteeism $[54,55]$. For instance, productivity impairments were assessed using the Work Productivity and Activity Impairment questionnaire in the Japan National Health and Wellness Surveys. While these types of studies do provide insights into the employment challenges faced by informal caregivers, they do not explicitly quantify or value the associated costs.

Most reports that have quantified the cost of informal care rely on estimates of the time caregivers spend in the provision of care. For instance, several

\section{Box 2: Indirect Costs-Key Takeaways}

- The main driver of indirect costs of ADRD is the unpaid work of informal caregivers, such as families and friends.

- The two most common approaches to quantifying the cost of informal care rely on estimates of the time caregivers spend in the provision of care. The 'replacement cost' approach values informal care time using the cost of an equivalent service bought in the market, while the 'opportunity cost (or human capital)' approach values informal care time by estimating the loss of labor market income.

- There is no unified consensus in the literature on the most appropriate approaches to estimate indirect costs in ADRD, and the choice of method and assumptions used can lead to striking variability in cost estimates.

- Notwithstanding the variabilities in informal care cost estimates, several studies have demonstrated a direct association between costs and disease severity; interestingly, there is evidence that the indirect costs of ADRD may also be elevated many years prior to a diagnosis of dementia.

- Emerging evidence suggests that informal caregivers may be forced to cut back on savings and expenditures, thereby threatening the financial security of households. This may be further exacerbated by the fact that many households will already be operating on fixed retirement incomes.

population-based studies, such as GERAS observational study in France, Germany, and the UK, and the European RightTimePlaceCare prospective cohort study, have relied on the RUD questionnaire (see 'Direct Costs', above). This instrument assesses the time caregivers spend on the provision of informal care such as Activities of Daily Living and Instrumental Activities of Daily Living, while also asking employed informal caregivers to state whether they had reduced their work hours and to what degree.

Questionnaires such as the RUD and the RUD-Lite form the foundation of two common approaches to quantifying the value of informal care costs; namely, the replacement cost approach $[48,56]$ and the opportunity cost approach (also referred to as the forgone wages or human capital approach) [21, 57-59]. The replacement cost approach values informal care time 
using the cost of an equivalent service bought in the market, such as the cost of a formal (paid) caregiver. The opportunity cost approach values informal care time by estimating the loss of labor market income using the caregiver's expected market wage, such as a national average wage.

The valuation (or costing) of informal care using these approaches, however, is challenging in practice $[9,50]$. For example, it is often difficult to delimit time spent by caregivers on different caregiving tasks, such as basic supervision or support with activities of daily living, which are self-reported and can occasionally erroneously exceed 24 hours per day in totality. A second major issue in the use of the opportunity cost approach is determining the most appropriate alternative use of the caregiver's time. While this is less of a challenge for employed caregivers, where the alternative is paid work, the valuation of time spent by unemployed or retired caregivers is not straightforward and different strategies have been adopted. For example, several studies segregate informal caregivers by employment status, and have reduced the opportunity cost of time for unemployed or retired caregivers to about $25-35 \%$ of average labor force wages, commonly referred to as the value of 'leisure time' [23-25, 58]. In another study, unpaid 'leisure time' in retired carers was valued based on average pension rates [60]. Another method has been to scale down the labor force wage rate by multiplying it by the rate of labor force participation in the same demographic group [61]. Another challenge, seldom discussed, is estimating the incremental or differential costs to caregivers based on their sex or relationship to the patient. For example, the majority, approximately two-thirds, of informal caregivers are women [6, 62-64], and a disproportionate burden of caregiving has been demonstrated to fall on wives and daughters compared to husbands and sons [65, 66]. The additional time that women invest in caring for someone with dementia is thought to contribute to higher levels of impaired mood, depression, and impaired health compared to men [6].

Informal care has also been valued using at least two other approaches, albeit less commonly than the methods described above. The contingent valuation approach $[8,20,26,67,68]$ is rooted in welfare economics and presents subjects with a hypothetical market situation to obtain their monetary valuation of a hypothetical change. In the case of ADRD, this method consists in valuing informal care using a 'price' the caregiver would be willing to pay to reduce caregiving time by one hour, or, alternatively, a willingness to accept a 'payment' to provide an additional hour of care. It has been suggested that such approaches can overcome the challenges associated with the valuation of leisure time described above and bring the added benefit of incorporating caregivers' preferences [68]. Finally, using a more direct approach, one study relying on records from the Danish National Patient Registry examined productivity losses in both patients (see below) and their partners, defined as an adult cohabitee, irrespective of gender. This approach is possible in Denmark as labor market income is registered in central databases that include all citizens.

Ultimately, the choice of method and assumptions used to value informal care can lead to striking variability in cost estimates. For example, using the same cohort of patients, annual informal caregiving was valued at US\$13,188 using the replacement costs approach but was valued at US\$27,789 using the opportunity cost approach [3]. Similarly, a study from Sweden found that informal costs can range from SEK 60 billion to SEK 124 billion depending on the approach used [69]. A systematic review conducted by ADI indicated that the proportion of total disease costs attributed to informal care ranged from $19 \%$ to $91 \%$ across studies, largely due to differences in the assumptions and approaches used to assess and value informal care [70]. ADI favors the use of the opportunity cost method $[9,50,70]$, and while no clear consensus has emerged in the published literature, several reports have prudently presented results using multiple approaches, typically as part of sensitivity analyses [8, 25, 26, 46, 47, 59, 61, 71-74].

\section{Patients: Productivity losses}

It has been noted that productivity losses in patients are generally less relevant in the context of ADRD, since most of those affected are older people who would in most cases be retired $[50,75]$. Nonetheless, productivity losses in patients have been assessed in several studies. However, it is challenging to conclusively assess the scale of productivity losses given the sensitivity of cost estimates on the approaches used. For example, in a comprehensive cost of illness study of moderate to severe dementia patients in fifteen European Union member states, productivity losses, including mortality and morbidity losses, accounted for only $€ 2.2$ billion $(1 \%)$ of total costs. In this study, morbidity losses were adjusted for the "friction period", a 90-day period of employee's absence from work due to illness before he or she is replaced 
by another worker. However, if morbidity losses were calculated using a human capital approach, productivity losses rose dramatically to $€ 7.3$ billion.

Productivity losses are also challenging to assess and compare across different studies due to several potential confounding factors such as differences in stages of illness in the populations examined, country-specific differences in labor marker wages or differences in the methods used in calculating costs. For example, one study estimated productivity losses due to premature mortality from AD based on US death certificates from 1999 to 2010 [76]. Using a human capital approach, the cost due to premature mortality was $\$ 4.4$ billion (2010 US dollars) over the period 1999 to 2010 [76]. While non-trivial, this pales in comparison to the total cost of ADRD, which has been estimated at US\$259 billion in the US in 2016 alone [77]. Another report using registry data from the Swedish Social Insurance Agency estimated productivity losses in individuals who were prematurely retired or on sick leave due to a dementia diagnosis [69]. At SEK118 million (2012), the productivity losses due to premature retirement or sick leave in Sweden represented only a minor component of total costs. A Danish study examined productivity losses in 78,715 patients and 312,813 matched controls up to 10 years prior to diagnosis [22]. In contrast to the above-mentioned studies, productivity losses due to forgone wages in patients comprised $18 \%$ to $36 \%$ of total per patient costs (Percentages are based on our calculations using the authors' reported raw costs. In that study total costs were defined as the sum outpatient and inpatient costs, medication, public health Insurance, and indirect costs such as foregone earnings) [22].

\section{Commentary}

The indirect costs of ADRD, in both patients and caregivers, become increasingly elevated years prior to a diagnosis of dementia

For example, in a Danish Study [22], employment rates and income from employment were lower in patients than in matched controls up to 10 years before diagnosis. Strikingly, partners of patients also had a lower employment rate and income than those in their control group, but this difference diminished after diagnosis.

\section{Informal costs of caring for community-dwelling ADRD patients increase with disease severity}

Most studies have assessed informal care costs as a consequence of caring for a patient diagnosed with dementia. Many studies of community-based patients have further segregated individuals according disease severity (e.g., mild, moderate, severe), typically based on measures such as Mini-Mental State Examination criteria or the Clinical Dementia Rating $[8,25$, $56,57,59,60,71,72,74,78,79]$. Despite the variabilities in informal care cost estimates, several crosssectional and longitudinal studies have demonstrated a direct association between costs and disease severity $[25,57,59,60,78]$. For instance, a longitudinal study using the population-based community cohort with dementia from the Cache County Study found that informal costs increased by approximately $18 \%$ per year, and that compared to very mild dementia, informal costs increased over 2-fold for mild, 5-fold for moderate and 6-fold for severe dementia $[57,80]$.

\section{The total financial impact of ADRD on households and the economy is substantial}

A recent survey by the Alzheimer's Association found that many informal caregivers were forced to cut back on expenditures on themselves and their families to support a relative or friend with ADRD. Notably, $20 \%$ of informal caregivers, including $45 \%$ of spouses/partners and $17 \%$ of children, reported having to spend money from their own retirement savings [53]. Reduced savings can impact the financial security not only of informal caregivers, but potentially also of their children and succeeding generations. Moreover, patients with MCI and dementia exhibit impairments in financial abilities and decision-making [81, 82], leading to increased vulnerability to financial exploitation and abuse, which is commonly associated with diminished or impaired mental capacities [83]. For example, True Link Financial, a financial-services firm, estimated annual losses in the US from financial abuse of the elderly at US\$36.48 billion each year, of which US\$16.99 billion is lost due to financial exploitation specifically designed to take advantage of older Americans [84]. Most approaches to value informal care, such as the opportunity or replacement cost methods, or productivity losses in patients, may not fully capture the financial burden on households such as reduced savings and therefore underestimate the indirect costs of the disease.

\section{INTANGIBLE COSTS}

Intangible costs are non-material costs which are not typically covered in economic analyses since they 
are better expressed in qualitative terms and do not easily lend themselves to monetization. Intangible costs apply to both patients and caregivers and stem from the deterioration of social, psychological, and physical domains of quality of life (QOL) (e.g., pain and suffering, impact on activities, use of time, personal relationships, and family) and/or exacerbation of comorbid illnesses. The economic translation of intangible costs is generally absent from studies that estimate the socioeconomic burden of ADRD [13].

\section{Patients: Quality of life and quality-adjusted life years}

Predominately two related methodologies have been used to evaluate the intangible costs for ADRD patients: namely, qualitative assessment of QOL through various scales and questionnaires and the quality-adjusted life year (QALY) concept.

At least 15 different instruments have been used to evaluate various domains of QOL or health-related quality of life (HRQOL) in ADRD patients [33, 85, 86]. QOL has been assessed with generic instruments, such as the EuroQol five-dimension questionnaire (EQ-5D) and 36-item Short-Form, as well dementiaspecific instruments, such as the Quality of Life in Alzheimer's Disease (QOL-AD) and Dementia Quality of Life questionnaire (DEMQOL). Both the QOL-AD and DEMQOL have been shown to be reliable and valid in patients with mild to moderate dementia and have been recommended as instruments of choice to assess QOL in clinical trials $[33,85]$. QOL measures can also be combined with AD-specific measures of symptoms, mental and/or physical functioning as well as determination of comorbid illness to provide a more holistic view of wellbeing and quality of life [55, 87]. Comorbidities are generally captured and rated using electronic health record data and/or questionnaires (e.g., Charlson comorbidity index).

However, there are several practical challenges that confound a comprehensive understanding of QOL in patients with ADRD [85, 88]. For instance, ADRD patients themselves may be unaware of the disease or its impact, and often exhibit reduced insight or ability to consistently assess wellbeing and QOL as cognitive function declines; moreover, the agreement between patient self-reported and caregiver proxy measures varies across studies [4]. Such confounding factors may contribute to the significant variability in reported QOL measures both within and across studies. For example, in one multi- center, longitudinal study in the UK, approximately equal proportions of patients reported declines or maintenance/improvements in QOL measures, with no significant group level changes over 18 months [88]. In contrast, group proxy ratings changed but depended on the instrument used; for example, EQ5D proxy data suggested an overall decline, while DEMQOL proxy data indicated an overall increase, in quality of life. Establishing a clear relationship between QOL and disease severity has also been challenging [88]. For example, some studies have shown that QOL declines for patients as the disease progresses [89-92], while others have found no clear or consistent relationships between QOL measures and disease severity [88, 93-95]. Please see Box 3 for a summary of key findings from this section.

\section{Box 3: Intangible Costs-Key Takeaways}

- Intangible costs in patients and caregivers have primarily been assessed using instruments that evaluate QOL in patients and caregivers; QALYs are commonly used in cost-effectiveness (or cost-utility) studies.

- Variability in the directionality of QOL changes both within and across studies has been noted. For example, some studies have shown that QOL declines for patients as the disease progresses, while others have found no clear or consistent relationship. Similarly, caregivers can experience both a rise or decline in QOL in response to caring for a person with ADRD.

- Challenges in quantifying the impact of ADRD on QOL may have important implications for the allocation of resources or reimbursement decisions. For example, different methodologies used to calculate QALYs may lead to contrasting results with respect to the cost-effectiveness of health interventions.

- Methodological limitations aside, several studies have shown a strong correlation between caregiving and health status of the caregiver; moreover, the subjective burden experienced by informal caregivers generally increases with disease severity.

- Notably, both QOL and caregiver burden may be impacted several years before the onset of dementia. 
The challenges in assessing QOL in ADRD may have important implications for the allocation of resources or reimbursement decisions, since the impact of interventions on QOL are increasingly being adopted in health technology assessments in several countries (e.g., UK, Canada, Sweden, Germany) $[86,96]$. One specific metric that is commonly used in cost-effectiveness (or cost-utility) studies is the QALY [96,97], which aims to combine mortality and morbidity into a single measurement. QALYs aim to quantify the impact of an intervention on both length of life and HRQOL. The use of QALYs in health economic assessments of interventions for ADRD, however, is controversial and challenging [5, 96, 98].

While numerous studies have assessed QOL in ADRD, relatively fewer have translated their findings into the health utility or health state values that are required for QALY calculations (see Box 4) [96]. Several QOL instruments such as the EQ-5D and DEMQOL have been used to quantify health utility weights in ADRD patients. Health utility values tend to decline with advancing disease severity, but a range of results have been reported within disease stages: mild AD (0.52-0.73); moderate AD (0.30-0.53); severe AD (0.12-0.49) [96]. Moreover, based on a recent meta-regression analysis [86], health state values can vary according to whether they rely on self-reported versus proxy data, the type of instrument used, and the modes of administration (e.g., face-to-face interview, survey, or phone interview). The authors of that study concluded that different approaches to assess utility values can result in significant differences in QALYs and may therefore lead to

Box 4: QALYs and Health States
The concept underlying a QALY is that patients
move through 'health states' over time, with each
health state having a value. QALYs are there-
fore calculated by multiplying the duration of time
spent in a health state by the HRQOL weight (or
utility) associated with that health state. Weights
are measured on a scale of 0 to 1 , where 0 indi-
cates death and 1 indicates best possible health.
Negative values indicate health states worse than
death. Weights can be generated by either direct
or generic preference-based measures. The lat-
ter includes questionnaires such as the EuroQol
(EQ)-5D, Short Form 6D, and the Health Utilities
Index.

contrasting results on the cost-effectiveness of health interventions.

\section{Caregivers: Quality of life and caregiving burden}

Caregiver QOL is evaluated using approaches similar to those used for patients, and in some cases the same scales can be applied to both caregivers and patients (e.g., EuroQoL, Short-Form Health Survey). However, more specific assessments (e.g., CareRelated QOL, Caregivers' QOL Index) have been developed to capture various dimensions unique to caregiver QOL [29]. The QOL of ADRD caregivers is a complex construct and is influenced by several factors [95]. For example, studies have shown that caregivers can experience both a rise or decline in QOL in response to caring for a person with ADRD. Improvements in QOL have been attributed to many factors such as a positive sense of accomplishment or strengthened family ties; deteriorations have been tied to the negative emotional, social, financial, or physical burden associated with caring for a person with ADRD. There is consensus that more sensitive instruments are needed to measure the QOL associated with caregiving for ADRD patients [4, 95].

Measures of caregiver 'burden' evaluate the tasks required to provide caregiving (objective burden) and the caregiver's perception on the degree to which caregiving has affected emotional, financial, physical and social functioning (subjective burden). The Zarit Burden Interview (ZBI) is one of the most commonly used scales to assess the subjective burden experienced by informal ADRD caregivers [24, 26, 74, 91, 99]. Similarly, the Caregiver Burden Inventory, among other instruments (e.g., Role Overload Scale, Caregiver Strain Index), have also been commonly used to measure the subjective and objective aspects of caregiver burden [29, 30, 56, 100]. As with patients, the Charlson comorbidity index is used to assess comorbid conditions in caregivers; however, there are numerous other instruments used in populations studies to gauge related aspects of health in caregivers, including depression (e.g., Center for Epidemiologic Studies Depression Scale), anxiety (e.g., Generalized Anxiety Disorder scale), mood (e.g., Positive and Negative Affect Scale), and sleep quality (e.g., Pittsburgh Sleep Quality Index) among others $[29,30,101-103]$. There is no clear consensus on the most appropriate instrument to use to gauge caregiver health status. 


\section{Commentary}

Figure 1 provides a depiction that represents the total burden of ADRD as not only measured societal costs but also hidden costs that, together with measured costs, represent a total burden that is much greater in magnitude and duration than is currently accurately assessed and appreciated.

\section{The intangible costs of ADRD appear to exist} years before the onset of dementia

Patients with subjective cognitive decline and MCI show a decline in almost every dimension of HRQOL compared with matched controls [104, 105]. Additionally, patients with MCI also contend with an increased risk of mortality [106]. Similarly, caregiver burden also extends before ADRD symptom onset in caregivers of patients with $\mathrm{MCI}$-depression and psychological comorbidity, although not as pronounced as in dementia caregivers, are common complications [107].

\section{Informal caregiver burden increases over time and with disease severity}

Several studies in community-dwelling ADRD patients have shown that caregiver burden, as measured with the ZBI questionnaire and other approaches, generally increases with disease severity, being directly related to patient functional abilities and level of dependence on the caregiver [91, 108, 109]. However, the link between caregiver QOL and the severity of dementia is currently unclear.

\section{Informal caregivers report poorer health status and greater comorbid disease risk compared with non-caregivers}

Several studies have demonstrated a strong correlation between caregiving and health status of the caregiver [29-31, 55, 99-102, 110-116]. For example, based on data from Brazil's National Health and Wellness Survey, caregiving was associated with significantly increased risk of depressive

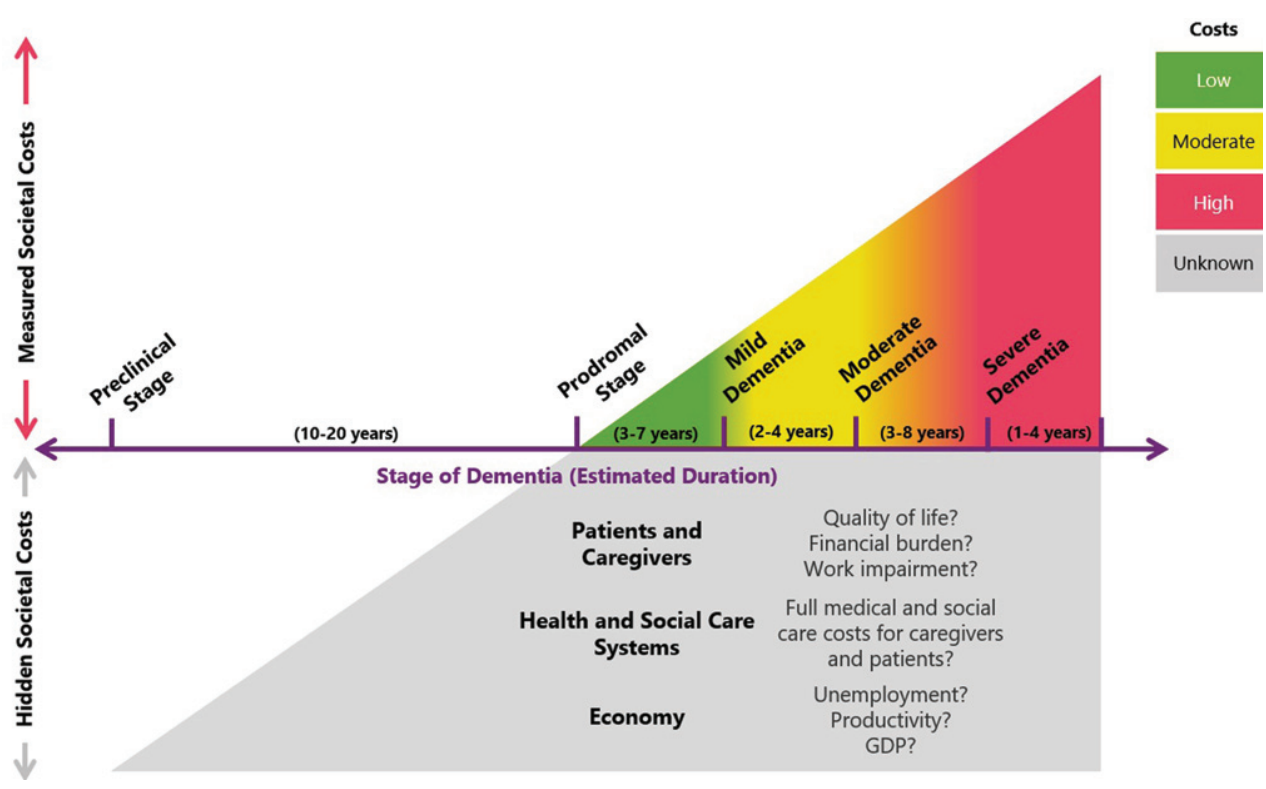

Fig. 1. Tip of the iceberg: Measured societal costs represent only a proportion of the total burden of ADRD. Most studies that have assessed the costs of ADRD have focused on patients with a dementia diagnosis and have generally demonstrated that costs increase with disease severity. However, such studies may not fully capture the total impact of ADRD for three reasons. First, the magnitude of indirect costs (e.g., lost productivity, informal caregiving) can vary widely depending on the methodologies and assumptions used. Second, cost of illness studies may not be measuring the full spectrum ADRD costs; for example, financial impacts on households (e.g., reduced savings, financial exploitation, out of pocket costs, unemployment) may have substantial and intergenerational effects on the economy. Finally, some studies suggest that costs begin to accrue years before a dementia diagnosis, albeit at a comparatively lower rate than those in advanced disease stages. However, given the long preclinical stage (estimated at 10-20 years), it is possible that these 'hidden costs' represent a substantial fraction of cumulative ADRD costs. Given the current evidence base, we cannot accurately gauge the size of these 'hidden costs', making it challenging to quantify the full burden of ADRD and the potential value of health interventions and policies. 
symptoms, anxiety, insomnia, hypertension, pain, and diabetes [87]. Similarly, a recent systematic review and meta-analysis found that the prevalence of depression among caregivers was $34.0 \%$, anxiety $43.6 \%$, and use of psychotropic drugs $27.2 \%$, with increased probability of depression in female and spousal caregivers [110]. Notably, female caregivers of ADRD patients are more likely to develop depression than male caregivers [110, 117]. The U.S. Alzheimer's Association recently estimated the physical and emotional impact of dementia caregiving to have resulted in US $\$ 11.8$ billion in health care costs in the U.S. in 2018 [6].

\section{CONCLUSIONS, RECOMMENDATIONS, AND OUTLOOK}

The magnitude and complexity of the socioeconomic costs of ADRD are staggering and rapidly increasing. Moreover, despite improvements in the quality of care for patients and the identification of several potentially modifiable risk factors [118], the causal mechanisms of ADRD are complex, multifactorial and not fully elucidated, and no disease-modifying intervention is available to delay, halt, or reverse the underlying pathology. Approved symptomatic treatments for AD (i.e., cholinesterase inhibitors and memantine), on average modestly improve or stabilize dementia-related cognitive and behavioral symptoms over short intervals of 6-12 months, and mitigate inevitable clinical decline over the course of several years [119-122]. Driven by greying populations across the globe, unrelenting growth in the prevalence of ADRD will therefore only magnify the human, societal, and economic burden of the disease-potentially overwhelming increasingly fragile support systems beyond the threshold of sustainability.

It is widely acknowledged that immediate policy action is necessary to curb the growing burden of ADRD in tandem with the ongoing efforts to develop more efficacious treatments or a prevention $[4,5,123-125]$. Success will require all stakeholders, including policymakers, healthcare industry leaders, advocacy groups, societies and associations, academia, biopharma, payers, clinicians, and researchers, to work shoulder-to-shoulder to address roadblocks that are hindering our understanding of the scope, scale and nature of the costs of ADRD so that we can develop, assess, and prioritize effective, evidence-based policies, strategies, and interventions to meet this growing global health crisis.

First, care for people with ADRD is provided by several sectors in society-with social care systems (e.g., long-term care and home services) and informal caregivers shouldering the greatest burden-and it is therefore difficult to isolate which sector is absorbing which costs. For example, most studies assessing direct costs of ADRD typically focus on the type of cost and generally do not distinguish which stakeholder absorbs the cost. Additionally, regions vary in the way that resources (and associated costs) are classified as belonging to the healthcare and/or social care systems, further complicating the task of delineating which stakeholder will shoulder the cost $[22,26,38]$. An added level of complexity in the ADRD arena is that informal care time could be framed or absorbed in diverse ways. For example, informal care could be viewed as an indirect cost absorbed by households (e.g., lost wages); however, if informal care is replaced by professional (paid) caregivers, it becomes a cost to health systems (or insurers), and paradoxically, a potential stimulus to the economy given that new jobs would be created.

Second, despite general agreement that indirect costs form a significant component of the total costs of ADRD, the quantification of these costs is problematic. Wide variability in cost estimates has been observed for informal care costs as well as productivity losses in patients, potentially due to differences in the methodologies used or study design. Furthermore, common approaches to valuing indirect costs may not fully capture other financial impacts on households, such as reduced expenditures or savings.

Third, a potentially massive component of the total cost of AD is 'hidden': symptoms and sequelae of the disease usually begin to manifest years, if not a decade, before diagnosis (see Fig. 2 for a conceptualized synthesis of the magnitude of costs borne by key stakeholders at different stages of disease). In the new National Institute on Aging-Alzheimer's Association (NIA-AA) AD Research Framework, $\mathrm{AD}$ is conceptualized pathobiologically on a pathological continuum measured by core biomarkers relating to abnormal amyloid, tau, and neurodegeneration, as opposed to being characterized by clinical symptoms relating to increasing severity of cognitive and functional deficits as well as behavioral changes $[19,126,127]$ (see Box 5). This shift in research thinking is likely to eventually have critical implications for clinical care, and in how we measure 


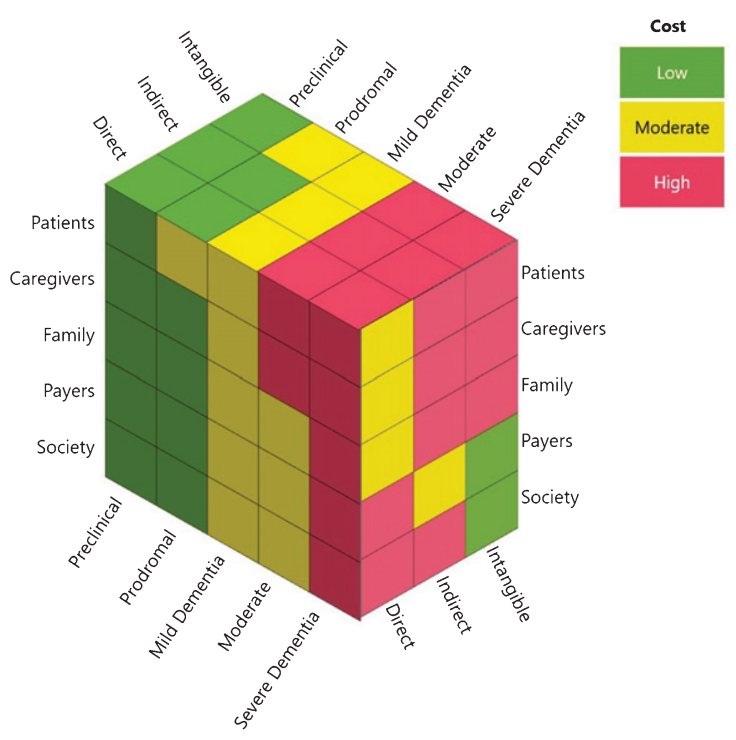

Fig. 2. The cost of ADRD across the spectrum of the disease to key stakeholders groups. The nature (i.e., direct, indirect, intangible) and magnitude (i.e., low, medium, high) of ADRD costs incurred by different stakeholders varies by the stage of disease (i.e., preclinical, prodromal, mild, moderate, severe).

\section{Box 5: The Evolving Definition of AD}

AD has traditionally been defined based on clinico-pathological criteria. However, based in part on advances in the use of biomarkers, a clinico-biological approach was adopted by the International Work Group and recently by the NIA-AA 2018 "Research Framework". Both approaches define AD biologically using biomarkers as proxies of neuropathology. Further, both approaches acknowledge $\mathrm{AD}$ as a pathologic continuum-a continuous process in both cognitive and biomarker domains, that can be divided into three clinical stages: a long preclinical period, followed by a prodromal or MCI phase with mild symptoms, and then dementia. However, the main update in the NIA-AA's 2018 Framework is that cognitive impairment is now viewed, in the research realm, as a symptom/sign of the disease rather than a requirement for defining $\mathrm{AD}$.

and assess the costs of the disease and the value of potential interventions. For instance, while most studies examining the costs of $\mathrm{AD}$ have focused on patients with dementia, there is evidence that the burden on patients, families and health systems may be elevated many years prior to a dementia diagnosis.
This suggests that a sizable portion of the burden of the disease could be hidden before dementia is clinically diagnosed. Moreover, a biological definition of $\mathrm{AD}$ based on biomarkers also raises the intriguing possibility of intervening at earlier stages of the disease continuum. Indeed, several reports have suggested that significant savings could be realized by either slowing/delaying disease progression through lifestyle modification [128-130] or promoting early diagnosis [49].

Finally, since ADRD are chronic, progressive disorders that often involve a decade or more of increasing and wide-ranging effects, assessing the full costs of disease and illness, or the full value of potential diagnostics and interventions, is not feasible during short-term studies involved in typical clinical trials $[4,28,131]$. Policymakers and stakeholders therefore need high-quality, long-term (ideally 5+ years), real-world data regarding disease progression rates, prevalence, costs, symptoms and clinical outcomes across the ADRD continuum to estimate future disease burden with confidence. However, such data are lacking $[4,5,28]$. While several studies have followed patients with ADRD longitudinally for periods up to 20 years (e.g., English Longitudinal Study on Aging, Swedish National Study on Aging) and may supply some of these data, these studies have generally been focused on patients with a dementia diagnosis and rely on a limited range of assessments $[4,28]$. One recently launched industrysponsored observational cohort study, the Insights to Model Alzheimer's Progression in Real Life (initiated in January 2019) [132], aims to assess the clinical meaningfulness of selected cognitive test scores that may track changes along the spectrum of preclinical $\mathrm{AD}$, prodromal $\mathrm{AD} / \mathrm{MCI}$ due to $\mathrm{AD}$, and dementia due to $\mathrm{AD}$, and to gather 5-years of longitudinal data on mortality, institutionalization, dependence, costs, caregiver burden, and QOL.

The potential impact of research efforts to assess the long-term utility and costs of diagnostics and interventions in real-world clinical settings, while still lacking, is supported by recent preliminary results of shorter-term studies with quasiexperimental (case-control) designs. For example, the IDEAS Study in the U.S. is one recent attempt to measure the clinical value of new diagnostics by looking at approximately 18,500 Medicare beneficiaries aged 65 years and older with MCI or dementia in which etiological diagnosis was found to be in doubt by a dementia specialist in order to assess the clinical impact of amyloid- $\beta$ PET 
scans on patient outcomes, treatments and costs. In this study, the US Centers for Medicare and Medicaid Services utilized the Coverage with Evidence Development mechanism to assess whether obtaining an amyloid- $\beta$ PET scan may lead to substantial changes in short-term, 90-day diagnosis and management, and in intermediate-term, 12-month clinical events (e.g., hospitalizations, emergency department visits, testing) and direct costs. The recently published results of the 90-day outcomes support that amyloid PET results significantly changed both the clinical diagnosis (from $\mathrm{AD}$ to non-AD disease in $25 \%$, and from non-AD to $\mathrm{AD}$ disease in 10\%) and the composite outcome of clinical management (e.g., medications, counseling, additional testing) (in 60-63\%) [133] — results that are consistent with the ABIDE study performed in 507 patients seen at two dementia specialty centers in the Netherlands [134].

While it is inherently challenging, due to practical considerations, to demonstrate significant short-term cost savings associated with "earlier" timely and accurate diagnosis of CID, if paired with appropriate care, it is a face-valid proposition that outcomes should be improved and "total" costs mitigated. An example of research that aims to address the latter regarding direct costs is from a recently published real-world quasi-experimental case-control interventional study, involving more than 1,000 Medicare beneficiaries (and 2,100 database controls) aged 65 and older, that assessed the utility of a 3-year comprehensive dementia clinical care intervention program that consisted of structured needs assessments of patients and their caregivers, implementation of individualized care plans with input from primary care physicians, monitoring and revising care plans, referral to community organizations for dementia-related services and support, and access to a clinician for assistance and advice 24 hours per day, 7 days per week. This study found a reduction of admissions to long-term care facilities and an average direct cost savings of US\$284 per participant per quarter (equivalent to US\$1,136 per year) [135]. Other interventional, care coordination, and real-world studies of care ecosystems are underway [136] and will be needed to provide the evidence-base to support the face validity that timely CID diagnosis and coordinated comprehensive support and care not only improve short- and long-term outcomes but also lead to longer term total cost savings.

In summary, the overall lack of up-to-date, comprehensive, and long-term "clinical effectiveness" data regarding real-world clinical outcomes and progression, and which also relate these outcomes to costs, burden, and impact parameters, constitute a major limitation of pharmacoeconomic models (e.g., decision analytical models) currently used at the policy level to quantify the effects of diagnostics and interventions for ADRD. Many such models have been informed by small sample sizes or are outdated; these include, for example, recent health technology appraisals of cholinesterase inhibitors and memantine by the National Institute for Health and Care Excellence (NICE) in the UK $[28,98]$.

\section{Recommendations}

It is evident that no single stakeholder can solve all the scientific, health system, and public health challenges related to ADRD experimental therapeutics, clinical care, prevention, and health care delivery alone. Such a complex problem requires solutions that involve collective commitment, collaboration, investment, and effort. Therefore, in line with recommendations from international groups and thought leaders $[118,123,137-141]$, there is an urgent need for integrated and innovative approaches to measure, manage and mitigate the burden of $\mathrm{AD}$ by:

- Developing and implementing better tools, measures, and programs to more accurately assess the real-world costs of ADRD. For example, leveraging new technologies such as wearables and apps to more frequently and accurately measure the time and burden of caregiving-related activities (e.g., on a daily basis as opposed to retrospective reports of previous 30 days or several months as used by current questionnaires), or to quantify the frequency, duration, and nature of resource utilization. Such data could then be directly linked to actual costs incurred via electronic health records billing, and pharmacy and insurance databases (e.g., in Medicare patients).

- Establishing pre-competitive investments in real-world population observational studies and registries across the continuum of aging, cognitive impairment, and dementia to examine the relationships between cognitive aging, comorbidities, and ADRD progression and costs across the totality of the aging, clinical syndromic, and disease spectrums. Also supporting real-world quasi-experimental and, when ethically possible, experimental studies to assess the clinical impact and long-term costs and ben- 
efits related to establishing and implementing best clinical practices [142] to improve timely diagnosis, disclosure, treatments, and care interventions in the CID spectrum due to ADRD.

- Establishing a better understanding of which stakeholder is ultimately absorbing the costs-whether health systems, insurers, social systems, employers, families or patients-to inform coordinated funding mechanisms for interventions and care paradigms that reflect all impacted "payers" and deliver greater value to patients, caregivers and their families (see Fig. 2).

- Building on an improved understanding of ADRD costs to develop more accurate costof-illness frameworks and forecasting models attuned to the socioeconomic realities of ADRD in order to support rational resource allocations and investment decisions.

- Investing and preparing for the advent of biomarker-based tests that can help accurately identify the hallmarks of ADRD and the contributions of multiple pathologies to clinical symptoms and CID, to improve provision of a timely diagnosis and to better inform prognosis and effects of early intervention and care. For example, fluid-based biomarkers, from blood and cerebrospinal fluid, and neuroimaging markers that could be employed in the use of potential future disease modifying therapies [122], which may have greatest impact at the earliest stages of disease, in order to select appropriate patients, and to monitor for safety and therapeutic effects.

- Ensuring that the assessment of the value of new treatment, management and care methods, whether care interventions, symptomatic treatments or disease modifying therapies for ADRD, account for their 'full value'-including their potential to alleviate direct, indirect and intangible costs affecting the broad spectrum of stakeholders impacted by the disease.

\section{Outlook}

Driven by greying populations across the globe, the costs of ADRD are predicted to become unsustainable. Although there is no cure, there is growing optimism that symptomatic stages of ADRD may be preventable or mitigated through a multi-pronged combination of risk factor reduction, early detection, novel therapeutics, and integrated care and support paradigms. A bold vision of a world in which ADRD is preventable and where patients and caregivers can receive the care and support needed to preserve a life of dignity and meaning was recently ratified at the 70th World Health Assembly, where member states endorsed an unprecedented global action plan on the public health response to dementia [123]. However, a centrally emergent theme from this review is that it is challenging to gauge the true value of policies, programs or interventions in the ADRD arena given the long-term, progressive nature of the disease, its insidious socioeconomic impact beyond the patient and the formal healthcare system, and the complexities and current deficiencies (in measures and real-world data) in accurately calculating the full costs to society. By extension, such challenges can obfuscate decision-making on the effective allocation of funds and resources across healthcare, social care and other relevant sectors. There is therefore an urgent need for all stakeholders to establish a common understanding of the challenges in evaluating the full cost of ADRD and define approaches that allow us to measure these costs more accurately, with a view to prioritizing evidence-based solutions to mitigate this looming public health crises.

\section{ACKNOWLEDGMENTS}

This work was partially sponsored by F. HoffmanLa Roche Ltd (see below). We would like to thank Jean Georges (Executive Director Alzheimer Europe) for his suggestions and feedback on early drafts of this manuscript.

Shift Health consults with organizations across the health and life sciences sector, including F. HoffmanLa Roche Ltd. Authors from Shift Health (REW, CPK, YEH, RD) were employed under contract with Hoffman-La Roche Ltd. for the purposes of this work. Authors not employed by Shift Health (CB, ARE, MK, JLM, MN, and AA) did not receive support or remuneration related to this work.

Authors' disclosures available online (https:// www.j-alz.com/manuscript-disclosures/19-0426).

\section{REFERENCES}

[1] GBD 2016 Dementia Collaborators (2019) Global, regional, and national burden of Alzheimer's disease and other dementias, 1990-2016: A systematic analysis for the Global Burden of Disease Study 2016. Lancet Neurol 18, 88-106. 
[2] Wimo A, Guerchet M, Ali G-C, Wu Y-T, Prina AM, Winblad B, Jönsson L, Liu Z, Prince M (2017) The worldwide costs of dementia 2015 and comparisons with 2010. Alzheimers Dement 13, 1-7.

[3] Yang Z, Lin P-J, Levey A (2013) Monetary costs of dementia in the United States. N Engl J Med 369, 489.

[4] Winblad B, Amouyel P, Andrieu S, Ballard C, Brayne C, Brodaty H, Cedazo-Minguez A, Dubois B, Edvardsson D, Feldman H, Fratiglioni L, Frisoni GB, Gauthier S, Georges J, Graff C, Iqbal K, Jessen F, Johansson G, Jönsson L, Kivipelto M, Knapp M, Mangialasche F, Melis R, Nordberg A, Rikkert MO, Qiu C, Sakmar TP, Scheltens P, Schneider LS, Sperling R, Tjernberg LO, Waldemar G, Wimo A, Zetterberg H (2016) Defeating Alzheimer's disease and other dementias: A priority for European science and society. Lancet Neurol 15, 455-532.

[5] Jönsson L, Lin P-J, Khachaturian AS (2017) Special topic section on health economics and public policy of Alzheimer's disease. Alzheimers Dement 13, 201-204.

[6] (2019) 2019 Alzheimer's disease facts and figures. Alzheimers Dement 15, 321-387.

[7] Atri A (2019) The Alzheimer's disease clinical spectrum: Diagnosis and management. Med Clin North Am 103, 263293.

[8] Farré M, Haro JM, Kostov B, Alvira C, Risco E, Miguel S, Cabrera E, Zabalegui A (2016) Direct and indirect costs and resource use in dementia care: A cross-sectional study in patients living at home. Int J Nurs Stud 55, 39-49.

[9] Prince M, Wimo A, Guerchet M, Ali G-C, Wu Y-T, Prina M (2015) World Alzheimer Report 2015. The Global Impact of Dementia: An analysis of prevalence, incidence, cost and trends. Alzheimer's Disease International, London, UK.

[10] Costa N, Derumeaux H, Rapp T, Garnault V, Ferlicoq L, Gillette S, Andrieu S, Vellas B, Lamure M, Grand A, Molinier L (2012) Methodological considerations in cost of illness studies on Alzheimer disease. Health Econ Rev 2,18 .

[11] Marešová P, Dolejš J, Kuca K (2018) Call for a uniform strategy of collecting Alzheimer's disease costs: A review and meta-analysis. J Alzheimers Dis 63, 227-238.

[12] Gilligan AM, Malone DC, Warholak TL, Armstrong EP (2013) Health disparities in cost of care in patients with Alzheimer's disease: An analysis across 4 state Medicaid populations. Am J Alzheimers Dis Other Demen 28, 84-92.

[13] Colucci L, Bosco M, Fasanaro AM, Gaeta GL, Ricci G, Amenta F (2014) Alzheimer's disease costs: What we know and what we should take into account. J Alzheimers Dis 42, 1311-1324.

[14] Deb A, Thornton JD, Sambamoorthi U, Innes K (2017) Direct and indirect cost of managing alzheimer's disease and related dementias in the United States. Expert Rev Pharmacoecon Outcomes Res 17, 189-202.

[15] Beach TG, Monsell SE, Phillips LE, Kukull W (2012) Accuracy of the clinical diagnosis of Alzheimer disease at National Institute on Aging Alzheimer Disease Centers, 2005-2010. J Neuropathol Exp Neurol 71, 266-273.

[16] Power MC, Mormino E, Soldan A, James BD, Yu L, Armstrong NM, Bangen KJ, Delano-Wood L, Lamar M, Lim YY, Nudelman K, Zahodne L, Gross AL, Mungas D, Widaman KF, Schneider J (2018) Combined neuropathological pathways account for age-related risk of dementia. Ann Neurol 84, 10-22.

[17] Boyle PA, Yu L, Leurgans SE, Wilson RS, Brookmeyer R, Schneider JA, Bennett DA (2019) Attributable risk of Alzheimer's dementia attributed to age-related neuropathologies. Ann Neurol 85, 114-124.

[18] Kapasi A, DeCarli C, Schneider JA (2017) Impact of multiple pathologies on the threshold for clinically overt dementia. Acta Neuropathol (Berl) 134, 171-186.

[19] Jack CR, Bennett DA, Blennow K, Carrillo MC, Dunn B, Haeberlein SB, Holtzman DM, Jagust W, Jessen F, Karlawish J, Liu E, Molinuevo JL, Montine T, Phelps C, Rankin KP, Rowe CC, Scheltens P, Siemers E, Snyder HM, Sperling R, Contributors (2018) NIA-AA Research Framework: Toward a biological definition of Alzheimer's disease. Alzheimers Dement 14, 535-562.

[20] Davidson M, Schnaider Beeri M (2000) Cost of Alzheimer's disease. Dialogues Clin Neurosci 2, 157-161.

[21] Dodel R, Belger M, Reed C, Wimo A, Jones RW, Happich M, Argimon JM, Bruno G, Vellas B, Haro JM (2015) Determinants of societal costs in Alzheimer's disease: GERAS study baseline results. Alzheimers Dement 11, 933-945.

[22] Frahm-Falkenberg S, Ibsen R, Kjellberg J, Jennum P (2016) Health, social and economic consequences of dementias: A comparative national cohort study. Eur $J$ Neurol 23, 1400-1407.

[23] Jones RW, Lebrec J, Kahle-Wrobleski K, Dell'Agnello G, Bruno G, Vellas B, Argimon JM, Dodel R, Haro JM, Wimo A, Reed C (2017) Disease progression in mild dementia due to Alzheimer disease in an 18-month observational study (GERAS): The impact on costs and caregiver outcomes. Dement Geriatr Cogn Disord Extra 7, 87-100.

[24] Lenox-Smith A, Reed C, Lebrec J, Belger M, Jones RW (2016) Resource utilisation, costs and clinical outcomes in non-institutionalised patients with Alzheimer's disease: 18-month UK results from the GERAS observational study. BMC Geriatr 16, 195.

[25] Wimo A, Reed CC, Dodel R, Belger M, Jones RW, Happich M, Argimon JM, Bruno G, Novick D, Vellas B, Haro JM (2013) The GERAS Study: A prospective observational study of costs and resource use in community dwellers with Alzheimer's disease in three European countries-study design and baseline findings. J Alzheimers Dis 36, 385-399.

[26] Wübker A, Zwakhalen SMG, Challis D, Suhonen R, Karlsson S, Zabalegui A, Soto M, Saks K, Sauerland D (2015) Costs of care for people with dementia just before and after nursing home placement: Primary data from eight European countries. Eur J Health Econ 16, 689-707.

[27] Zhu CW, Scarmeas N, Torgan R, Albert M, Brandt J, Blacker D, Sano M, Stern Y (2006) Longitudinal study of effects of patient characteristics on direct costs in Alzheimer disease. Neurology 67, 998-1005.

[28] Gustavsson A, Green C, Jones RW, Förstl H, Simsek D, de Reydet de Vulpillieres F, Luthman S, Adlard N, Bhattacharyya S, Wimo A (2017) Current issues and future research priorities for health economic modelling across the full continuum of Alzheimer's disease. Alzheimers Dement 13, 312-321.

[29] Mausbach BT, Chattillion EA, Roepke SK, Patterson TL, Grant I (2013) A comparison of psychosocial outcomes in elderly Alzheimer caregivers and noncaregivers. Am J Geriatr Psychiatry 21, 5-13.

[30] von Känel R, Mills PJ, Mausbach BT, Dimsdale JE, Patterson TL, Ziegler MG, Ancoli-Israel S, Allison M, Chattillion EA, Grant I (2012) Effect of Alzheimer caregiving on circulating levels of C-reactive protein and other 
biomarkers relevant to cardiovascular disease risk: A longitudinal study. Gerontology 58, 354-365.

[31] Zhu CW, Scarmeas N, Ornstein K, Albert M, Brandt J, Blacker D, Sano M, Stern Y (2015) Health-care use and cost in dementia caregivers: Longitudinal results from the Predictors Caregiver Study. Alzheimers Dement 11, 444454.

[32] Suehs BT, Shah SN, Davis CD, Alvir J, Faison WE, Patel NC, van Amerongen D, Bobula J (2014) Household members of persons with Alzheimer's disease: Health conditions, healthcare resource use, and healthcare costs. $J \mathrm{Am}$ Geriatr Soc 62, 435-441.

[33] Yang F, Dawes P, Leroi I, Gannon B (2018) Measurement tools of resource use and quality of life in clinical trials for dementia or cognitive impairment interventions: A systematically conducted narrative review. Int $J$ Geriatr Psychiatry 33, e166-e176.

[34] Wimo A, Gustavsson A, Jönsson L, Winblad B, Hsu M-A, Gannon B (2013) Application of Resource Utilization in Dementia (RUD) instrument in a global setting. Alzheimers Dement 9, 429-435.e17.

[35] Gorina Y, Kramarow EA (2011) Identifying chronic conditions in Medicare claims data: Evaluating the Chronic Condition Data Warehouse algorithm. Health Serv Res 46, 1610-1627.

[36] Taylor DH, Østbye T, Langa KM, Weir D, Plassman BL (2009) The accuracy of Medicare claims as an epidemiological tool: The case of dementia revisited. J Alzheimers Dis 17, 807-815.

[37] Hunter CA, Kirson NY, Desai U, Cummings AKG, Faries DE, Birnbaum HG (2015) Medical costs of Alzheimer's disease misdiagnosis among US Medicare beneficiaries. Alzheimers Dement 11, 887-895.

[38] Brüggenjürgen B, Andersohn F, Ezzat N, Lacey L, Willich S (2015) Medical management, costs, and consequences of Alzheimer's disease in Germany: An analysis of health claims data. J Med Econ 18, 466-473.

[39] Browne J, Edwards DA, Rhodes KM, Brimicombe DJ, Payne RA (2017) Association of comorbidity and health service usage among patients with dementia in the UK: A population-based study. BMJ Open 7, e012546.

[40] Kuo T-C, Zhao Y, Weir S, Kramer MS, Ash AS (2008) Implications of comorbidity on costs for patients with Alzheimer disease. Med Care 46, 839-846.

[41] Hunger M, Schwarzkopf L, Heier M, Peters A, Holle R, KORA Study Group (2013) Official statistics and claims data records indicate non-response and recall bias within survey-based estimates of health care utilization in the older population. BMC Health Serv Res 13, 1.

[42] Lin P-J, Zhong Y, Fillit HM, Chen E, Neumann PJ (2016) Medicare expenditures of individuals with Alzheimer's disease and related dementias or mild cognitive impairment before and after diagnosis. $J$ Am Geriatr Soc 64, 1549-1557.

[43] Geldmacher DS, Kirson NY, Birnbaum HG, Eapen S, Kantor E, Cummings AK, Joish VN (2013) Pre-diagnosis excess acute care costs in Alzheimer's patients among a US Medicaid population. Appl Health Econ Health Policy 11, 407-413.

[44] Taipale H, Purhonen M, Tolppanen A, Tanskanen A, Tiihonen J, Hartikainen S (2016) Hospital care and drug costs from five years before until two years after the diagnosis of Alzheimer's disease in a Finnish nationwide cohort. Scand J Public Health 44, 150-158.
[45] Fong TG, Davis D, Growdon ME, Albuquerque A, Inouye SK (2015) The interface of delirium and dementia in older persons. Lancet Neurol 14, 823-832.

[46] Ku L-JE, Pai M-C, Shih P-Y (2016) Economic impact of dementia by disease severity: Exploring the relationship between stage of dementia and cost of care in Taiwan. PLoS One 11, e0148779.

[47] König H-H, Leicht H, Brettschneider C, Bachmann C, Bickel H, Fuchs A, Jessen F, Köhler M, Luppa M, Mösch E, Pentzek M, Werle J, Weyerer S, Wiese B, Scherer M, Maier W, Riedel-Heller SG, AgeCoDe Study Group (2014) The costs of dementia from the societal perspective: Is care provided in the community really cheaper than nursing home care? J Am Med Dir Assoc 15, 117-126.

[48] Kelley AS, McGarry K, Gorges R, Skinner JS (2015) The burden of health care costs in the last 5 years of life. Ann Intern Med 163, 729-736.

[49] (2018) 2018 Alzheimer's disease facts and figures. Alzheimers Dement 14, 367-429.

[50] Wimo A, Prince M (2010) World Alzheimer Report 2010. The Global Economic Impact of Dementia. Alzheimer's Disease International, London, UK.

[51] Jutkowitz E, Kane RL, Gaugler JE, MacLehose RF, Dowd B, Kuntz KM (2017) Societal and family lifetime cost of dementia: Implications for policy. J Am Geriatr Soc $\mathbf{6 5}$, 2169-2175.

[52] Supporting employees who are caring for someone with dementia - Carers UK.

[53] Alzheimer's Association (2016) 2016 Alzheimer's disease facts and figures. Alzheimers Dement 12, 459-509.

[54] Wolff JL, Spillman BC, Freedman VA, Kasper JD (2016) A national profile of family and unpaid caregivers who assist older adults with health care activities. JAMA Intern Med 176, 372-379.

[55] Goren A, Montgomery W, Kahle-Wrobleski K, Nakamura T, Ueda K (2016) Impact of caring for persons with Alzheimer's disease or dementia on caregivers' health outcomes: Findings from a community based survey in Japan. BMC Geriatr 16, 122.

[56] Chiatti C, Furneri G, Rimland JM, Demma F, Bonfranceschi F, Cassetta L, Masera F, Cherubini A, Corsonello A, Lattanzio F, UP-TECH research group (2015) The economic impact of moderate stage Alzheimer's disease in Italy: Evidence from the UP-TECH randomized trial. Int Psychogeriatr 27, 1563-1572.

[57] Rattinger GB, Schwartz S, Mullins CD, Corcoran C, Zuckerman IH, Sanders C, Norton MC, Fauth EB, Leoutsakos J-MS, Lyketsos CG, Tschanz JT (2015) Dementia severity and the longitudinal costs of informal care in the Cache County Population. Alzheimers Dement 11, 946-954.

[58] Gillespie P, O'Shea E, Cullinan J, Buchanan J, Bobula J, Lacey L, Gallagher D, Mhaolain AN, Lawlor B, Enhancing Care in Alzheimer's Disease (ECAD) Study Team (2015) Longitudinal costs of caring for people with Alzheimer's disease. Int Psychogeriatr 27, 847-856.

[59] Zhu CW, Scarmeas N, Torgan R, Albert M, Brandt J, Blacker D, Sano M, Stern Y (2006) Clinical characteristics and longitudinal changes of informal cost of Alzheimer's disease in the community. $J$ Am Geriatr Soc 54, 15961602.

[60] Gervès C, Chauvin P, Bellanger MM (2014) Evaluation of full costs of care for patients with Alzheimer's disease in France: The predominant role of informal care. Health Policy 116, 114-122. 
[61] Darbà J, Kaskens L (2015) Relationship between patient dependence and direct medical-, social-, indirect-, and informal-care costs in Spain. Clin Outcomes Res 7, 387395.

[62] Kasper JD, Freedman VA, Spillman BC, Wolff JL (2015) The disproportionate impact of dementia on family and unpaid caregiving to older adults. Health Aff (Millwood) 34, 1642-1649.

[63] Alzheimer's Research UK (2015) Women and Dementia: A Marginalised Majority. https://www.alzheimersresear chuk.org/about-us/our-influence/policy-work/reports/wo men-dementia/

[64] Global Alzheimer's \& Dementia Action Alliance (2017) Women \& Dementia-A Global Challenge. https://www.gadaalliance.org/report-women-dementia-aglobal-challenge/

[65] Yang Z, Levey A (2015) Gender differences: A lifetime analysis of the economic burden of Alzheimer's disease. Womens Health Issues 25, 436-440.

[66] Stewart NJ, Morgan DG, Karunanayake CP, Wickenhauser JP, Cammer A, Minish D, O'Connell ME, Hayduk LA (2016) Rural caregivers for a family member with dementia: Models of burden and distress differ for women and men. J Appl Gerontol 35, 150-178.

[67] van den Berg B, Brouwer W, van Exel J, Koopmanschap M (2005) Economic valuation of informal care: The contingent valuation method applied to informal caregiving. Health Econ 14, 169-183.

[68] Gustavsson A, Jönsson L, McShane R, Boada M, Wimo A, Zbrozek AS (2010) Willingness-to-pay for reductions in care need: Estimating the value of informal care in Alzheimer's disease. Int J Geriatr Psychiatry 25, 622-632.

[69] Wimo A, Jönsson L, Fratiglioni L, Sandman PO, Gustavsson A, Sköldunger A, Johansson L (2016) The societal costs of dementia in Sweden 2012 - relevance and methodological challenges in valuing informal care. Alzheimers Res Ther 8, 59.

[70] Prince M, Prina M, Guerchet M (2013) World Alzheimer Report 2013. Journey of Caring: An analysis of longterm care for dementia. Alzheimer's Disease International, London, UK.

[71] Michalowsky B, Flessa S, Eichler T, Hertel J, Dreier A, Zwingmann I, Wucherer D, Rau H, Thyrian JR, Hoffmann W (2018) Healthcare utilization and costs in primary care patients with dementia: Baseline results of the DelpHitrial. Eur J Health Econ 19, 87-102.

[72] Holmerová I, Hort J, Rusina R, Wimo A, Šteffl M (2017) Costs of dementia in the Czech Republic. Eur J Health Econ 18, 979-986.

[73] Michalowsky B, Thyrian JR, Eichler T, Hertel J, Wucherer D, Flessa S, Hoffmann W (2016) Economic analysis of formal care, informal care, and productivity losses in primary care patients who screened positive for dementia in Germany. J Alzheimers Dis 50, 47-59.

[74] Gustavsson A, Brinck P, Bergvall N, Kolasa K, Wimo A, Winblad B, Jönsson L (2011) Predictors of costs of care in Alzheimer's disease: A multinational sample of 1222 patients. Alzheimers Dement 7, 318-327.

[75] Luengo-Fernandez R, Leal J, Gray AM (2011) Cost of dementia in the pre-enlargement countries of the European Union. J Alzheimers Dis 27, 187-196.

[76] Moschetti K, Barragan N, Basurto-Dávila R, Cummings PL, Sorvillo F, Kuo T (2015) Mortality and productivity losses from Alzheimer disease among US adults aged 40 to 64 years, 1999 to 2010. Alzheimer Dis Assoc Disord 29, 165-168.

[77] (2017) 2017 Alzheimer's disease facts and figures. Alzheimers Dement 13, 325-373.

[78] Lacey L, Bobula J, Niecko T, Leibman C (2017) Informal care time and cost in a large clinical trial sample of patients with mild to moderate Alzheimer's disease: Determinants and level of change observed. Neurol Ther $\mathbf{6}$, 11-23.

[79] Cheng S-T (2017) Dementia caregiver burden: A research update and critical analysis. Curr Psychiatry Rep 19, 64.

[80] Rattinger GB, Fauth EB, Behrens S, Sanders C, Schwartz S, Norton MC, Corcoran C, Mullins CD, Lyketsos CG, Tschanz JT (2016) Closer caregiver and care-recipient relationships predict lower informal costs of dementia care: The Cache County Dementia Progression Study. Alzheimers Dement 12, 917-924.

[81] Marson DC, Sawrie SM, Snyder S, McInturff B, Stalvey T, Boothe A, Aldridge T, Chatterjee A, Harrell LE (2000) Assessing financial capacity in patients with Alzheimer disease: A conceptual model and prototype instrument. Arch Neurol 57, 877-884.

[82] Sudo FK, Laks J (2017) Financial capacity in dementia: A systematic review. Aging Ment Health 21, 677-683.

[83] Marson DC (2013) Clinical and ethical aspects of financial capacity in dementia: A commentary. Am J Geriatr Psychiatry 21, 382-390.

[84] True Link: Research - Report on Elder Financial Abuse. https://www.truelinkfinancial.com/true-link-report-on-el der-financial-abuse-012815

[85] Bowling A, Rowe G, Adams S, Sands P, Samsi K, Crane M, Joly L, Manthorpe J (2015) Quality of life in dementia: A systematically conducted narrative review of dementiaspecific measurement scales. Aging Ment Health 19, 1331.

[86] Li L, Nguyen K-H, Comans T, Scuffham P (2018) Utilitybased instruments for people with dementia: A systematic review and meta-regression analysis. Value Health 21, 471-481.

[87] Laks J, Goren A, Dueñas H, Novick D, Kahle-Wrobleski K (2016) Caregiving for patients with Alzheimer's disease or dementia and its association with psychiatric and clinical comorbidities and other health outcomes in Brazil. Int $J$ Geriatr Psychiatry 31, 176-185.

[88] Trigg R, Jones RW, Knapp M, King D, Lacey LA, DADE2 Investigator Groups (2015) The relationship between changes in quality of life outcomes and progression of Alzheimer's disease: Results from the dependence in AD in England 2 longitudinal study. Int J Geriatr Psychiatry 30, 400-408.

[89] Castro-Monteiro E, Forjaz MJ, Ayala A, RodriguezBlazquez C, Fernandez-Mayoralas G, Diaz-Redondo A, Martinez-Martin P (2014) Change and predictors of quality of life in institutionalized older adults with dementia. Qual Life Res 23, 2595-2601.

[90] Vogel A, Bhattacharya S, Waldorff FB, Waldemar G (2012) Proxy-rated quality of life in Alzheimer's disease: A three-year longitudinal study. Int Psychogeriatr 24, 8289.

[91] Jones RW, Romeo R, Trigg R, Knapp M, Sato A, King D, Niecko T, Lacey L, DADE Investigator Group (2015) Dependence in Alzheimer's disease and service use costs, quality of life, and caregiver burden: The DADE study. Alzheimers Dement 11, 280-290. 
[92] Heßmann P, Seeberg G, Reese JP, Dams J, Baum E, Müller MJ, Dodel R, Balzer-Geldsetzer M (2016) Health-related quality of life in patients with Alzheimer's disease in different German health care settings. J Alzheimers Dis 51, 545-561.

[93] Conde-Sala JL, Turró-Garriga O, Calvó-Perxas L, VilaltaFranch J, Lopez-Pousa S, Garre-Olmo J (2014) Three-year trajectories of caregiver burden in Alzheimer's disease. $J$ Alzheimers Dis 42, 623-633.

[94] Yu H, Gao C, Zhang Y, He R, Zhou L, Liang R (2017) Trajectories of health-related quality of life during the natural history of dementia: A six-wave longitudinal study. Int $J$ Geriatr Psychiatry 32, 940-948.

[95] Farina N, Page TE, Daley S, Brown A, Bowling A, Basset T, Livingston G, Knapp M, Murray J, Banerjee S (2017) Factors associated with the quality of life of family carers of people with dementia: A systematic review. Alzheimers Dement 13, 572-581.

[96] Shearer J, Green C, Ritchie CW, Zajicek JP (2012) Health state values for use in the economic evaluation of treatments for Alzheimer's disease. Drugs Aging 29, 31-43.

[97] Whitehead SJ, Ali S (2010) Health outcomes in economic evaluation: The QALY and utilities. Br Med Bull 96, 5-21.

[98] Getsios D, Migliaccio-Walle K, Caro JJ (2007) NICE costeffectiveness appraisal of cholinesterase inhibitors: Was the right question posed? Were the best tools used? Pharmacoeconomics 25, 997-1006.

[99] Andrieu S, Coley N, Rolland Y, Cantet C, Arnaud C, Guyonnet S, Nourhashemi F, Grand A, Vellas B, PLASA group (2016) Assessing Alzheimer's disease patients' quality of life: Discrepancies between patient and caregiver perspectives. Alzheimers Dement 12, 427-437.

[100] Jennings LA, Reuben DB, Evertson LC, Serrano KS, Ercoli L, Grill J, Chodosh J, Tan Z, Wenger NS (2015) Unmet needs of caregivers of individuals referred to a dementia care program. J Am Geriatr Soc 63, 282-289.

[101] Liu S, Li C, Shi Z, Wang X, Zhou Y, Liu S, Liu J, Yu T, Ji Y (2017) Caregiver burden and prevalence of depression, anxiety and sleep disturbances in Alzheimer's disease caregivers in China. J Clin Nurs 26, 1291-1300.

[102] Borsje P, Hems MAP, Lucassen PLBJ, Bor H, Koopmans RTCM, Pot AM (2016) Psychological distress in informal caregivers of patients with dementia in primary care: Course and determinants. Fam Pract 33, 374-381.

[103] Papastavrou E, Andreou P, Middleton N, Papacostas S, Georgiou IK (2014) Factors associated with quality of life among family members of patients with dementia in Cyprus. Int Psychogeriatr 26, 443-452.

[104] Pusswald G, Moser D, Pflüger M, Gleiss A, Auff E, Stögmann E, Dal-Bianco P, Lehrner J (2016) The impact of depressive symptoms on health-related quality of life in patients with subjective cognitive decline, mild cognitive impairment, and Alzheimer's disease. Int Psychogeriatr 28, 2045-2054.

[105] Pusswald G, Tropper E, Kryspin-Exner I, Moser D, Klug S, Auff E, Dal-Bianco P, Lehrner J (2015) Health-related quality of life in patients with subjective cognitive decline and mild cognitive impairment and its relation to activities of daily living. J Alzheimers Dis 47, 479-486.

[106] Vos SJ, Xiong C, Visser PJ, Jasielec MS, Hassenstab J, Grant EA, Cairns NJ, Morris JC, Holtzman DM, Fagan AM (2013) Preclinical Alzheimer's disease and its outcome: A longitudinal cohort study. Lancet Neurol 12, 957-965.
[107] Seeher K, Low L-F, Reppermund S, Brodaty H (2013) Predictors and outcomes for caregivers of people with mild cognitive impairment: A systematic literature review. Alzheimers Dement 9, 346-355.

[108] Haro JM, Kahle-Wrobleski K, Bruno G, Belger M, Dell'Agnello G, Dodel R, Jones RW, Reed CC, Vellas B, Wimo A, Argimon JM (2014) Analysis of burden in caregivers of people with Alzheimer's disease using self-report and supervision hours. J Nutr Health Aging 18, 677-684.

[109] Reed C, Belger M, Dell'agnello G, Wimo A, Argimon JM, Bruno G, Dodel R, Haro JM, Jones RW, Vellas B (2014) Caregiver burden in Alzheimer's disease: Differential associations in adult-child and spousal caregivers in the GERAS Observational Study. Dement Geriatr Cogn Disord Extra 4, 51-64.

[110] Sallim AB, Sayampanathan AA, Cuttilan A, Ho R (2015) Prevalence of mental health disorders among caregivers of patients with Alzheimer disease. J Am Med Dir Assoc 16, 1034-1041.

[111] Fonareva I, Oken BS (2014) Physiological and functional consequences of caregiving for relatives with dementia. Int Psychogeriatr 26, 725-747.

[112] Bremer P, Cabrera E, Leino-Kilpi H, Lethin C, Saks K, Sutcliffe C, Soto M, Zwakhalen SMG, Wübker A, RightTimePlaceCare Consortium (2015) Informal dementia care: Consequences for caregivers' health and health care use in 8 European countries. Health Policy 119, 14591471.

[113] Roepke SK, Allison M, Von Känel R, Mausbach BT, Chattillion EA, Harmell AL, Patterson TL, Dimsdale JE, Mills PJ, Ziegler MG, Ancoli-Israel S, Grant I (2012) Relationship between chronic stress and carotid intima-media thickness (IMT) in elderly Alzheimer's disease caregivers. Stress 15, 121-129.

[114] Peña-Longobardo LM, Oliva-Moreno J (2015) Caregiver burden in Alzheimer's disease patients in Spain. $J$ Alzheimers Dis 43, 1293-1302.

[115] Abdollahpour I, Nedjat S, Noroozian M, Salimi Y, Majdzadeh R (2014) Caregiver burden: The strongest predictor of self-rated health in caregivers of patients with dementia. J Geriatr Psychiatry Neurol 27, 172-180.

[116] Martindale-Adams J, Nichols LO, Zuber J, Burns R, Graney MJ (2016) Dementia caregivers' use of services for themselves. Gerontologist 56, 1053-1061.

[117] Jang S-I, Bae H-C, Shin J, Jang S-Y, Hong S, Han K-T, Park E-C (2016) Depression in the family of patients with dementia in Korea. Am J Alzheimers Dis Other Demen 31, 481-491.

[118] Livingston G, Sommerlad A, Orgeta V, Costafreda SG, Huntley J, Ames D, Ballard C, Banerjee S, Burns A, Cohen-Mansfield J, Cooper C, Fox N, Gitlin LN, Howard R, Kales HC, Larson EB, Ritchie K, Rockwood K, Sampson EL, Samus Q, Schneider LS, Selbæk G, Teri L, Mukadam N (2017) Dementia prevention, intervention, and care. Lancet 390, 2673-2734.

[119] Atri A, Shaughnessy LW, Locascio JJ, Growdon JH (2008) Long-term course and effectiveness of combination therapy in Alzheimer disease. Alzheimer Dis Assoc Disord 22, 209-221.

[120] Atri A, Hendrix SB, Pejović V, Hofbauer RK, Edwards J, Molinuevo JL, Graham SM (2015) Cumulative, additive benefits of memantine-donepezil combination over component monotherapies in moderate to severe Alzheimer's dementia: A pooled area under the curve analysis. Alzheimers Res Ther 7, 28. 
[121] Rountree SD, Atri A, Lopez OL, Doody RS (2013) Effectiveness of antidementia drugs in delaying Alzheimer's disease progression. Alzheimers Dement 9, 338-345.

[122] Atri A (2019) Current and future treatments in Alzheimer's disease. Semin Neurol 39, 227-240.

[123] World Health Organization. Global action plan on the public health response to dementia $2017-2025$.

[124] OECD (2015) Addressing Dementia: The OECD Response. OECD Health Policy Studies, OECD Publishing, Paris, https://doi.org/10.1787/9789264231726-en.

[125] World Health Organization. Dementia: A public health priority.

[126] Molinuevo JL, Minguillon C, Rami L, Gispert JD (2018) The rationale behind the new Alzheimer's disease conceptualization: Lessons learned during the last decades. $J$ Alzheimers Dis 62, 1067-1077.

[127] Dubois B, Hampel H, Feldman HH, Scheltens P, Aisen $\mathrm{P}$, Andrieu S, Bakardjian $\mathrm{H}$, Benali $\mathrm{H}$, Bertram L, Blennow K, Broich K, Cavedo E, Crutch S, Dartigues J-F, Duyckaerts C, Epelbaum S, Frisoni GB, Gauthier S, Genthon R, Gouw AA, Habert M-O, Holtzman DM, Kivipelto M, Lista S, Molinuevo J-L, O'Bryant SE, Rabinovici GD, Rowe C, Salloway S, Schneider LS, Sperling R, Teichmann M, Carrillo MC, Cummings J, Jack CR, Proceedings of the Meeting of the International Working Group (IWG) and the American Alzheimer's Association on "The Preclinical State of AD"; July 23, 2015; Washington DC, USA (2016) Preclinical Alzheimer's disease: Definition, natural history, and diagnostic criteria. Alzheimers Dement 12, 292-323.

[128] Lin P-J, Yang Z, Fillit HM, Cohen JT, Neumann PJ (2014) Unintended benefits: The potential economic impact of addressing risk factors to prevent Alzheimer's disease. Health Aff (Millwood) 33, 547-554.

[129] Norton S, Matthews FE, Barnes DE, Yaffe K, Brayne C (2014) Potential for primary prevention of Alzheimer's disease: An analysis of population-based data. Lancet Neurol 13, 788-794.

[130] Zhang Y, Kivipelto M, Solomon A, Wimo A (2011) Costeffectiveness of a health intervention program with risk reductions for getting demented: Results of a Markov model in a Swedish/Finnish setting. J Alzheimers Dis 26, 735-744.

[131] Wimo A, Ballard C, Brayne C, Gauthier S, Handels R, Jones RW, Jonsson L, Khachaturian AS, Kramberger M (2014) Health economic evaluation of treatments for Alzheimer's disease: Impact of new diagnostic criteria. $J$ Intern Med 275, 304-316.

[132] Graf A, Risson V, Gustavsson A, Bezlyak V, Caputo A, Tariot PN, Langbaum JB, Lopez Lopez C, Viglietta V (2019) Assessment of clinical meaningfulness of endpoints in the generation program by the insights to model Alzheimer's progression in real life (iMAP) study. J Prev Alzheimers Dis 6, 85-89.
[133] Rabinovici GD, Gatsonis C, Apgar C, Gareen IF, Hanna L, Hendrix J, Hillner BE, Olson C, Romanoff J, Siegel BA, Whitmer RA, Carrillo MC (2017) Impact of amyloid pet on patient management: Early results from the ideas study. Alzheimers Dement 13, P1474.

[134] de Wilde A, van der Flier WM, Pelkmans W, Bouwman F, Verwer J, Groot C, van Buchem MM, Zwan M, Ossenkoppele R, Yaqub M, Kunneman M, Smets EMA, Barkhof F, Lammertsma AA, Stephens A, van Lier E, Biessels GJ, van Berckel BN, Scheltens P (2018) Association of amyloid positron emission tomography with changes in diagnosis and patient treatment in an unselected memory clinic cohort: The ABIDE Project. JAMA Neurol 75, 1062-1070.

[135] Jennings LA, Laffan AM, Schlissel AC, Colligan E, Tan Z, Wenger NS, Reuben DB (2019) Health care utilization and cost outcomes of a comprehensive dementia care program for medicare beneficiaries. JAMA Intern Med 179, 161166.

[136] Possin KL, Merrilees J, Bonasera SJ, Bernstein A, Chiong W, Lee K, Wilson L, Hooper SM, Dulaney S, Braley T, Laohavanich S, Feuer JE, Clark AM, Schaffer MW, Schenk AK, Heunis J, Ong P, Cook KM, Bowhay AD, Gearhart R, Chodos A, Naasan G, Bindman AB, Dohan D, Ritchie C, Miller BL (2017) Development of an adaptive, personalized, and scalable dementia care program: Early findings from the Care Ecosystem. PLoS Med 14, e1002260.

[137] World Health Organization. Towards a dementia plan: A WHO guide.

[138] Alzheimer's Disease and Dementia, Alzheimer's Association Annual Report Fiscal Year 2017 (July 1, 2016 - June 30, 2017).

[139] ASPE, National Plan to Address Alzheimer's Disease: 2017 Update. https://aspe.hhs.gov/national-plansaddress-alzheimers-disease.

[140] World Health Organization. First WHO Ministerial Conference on Global Action Against Dementia.

[141] Prince M, Comas-Herrera A, Knapp M, Guerchet M, Karagiannidou M (2016) World Alzheimer Report 2016. Improving healthcare for people living with dementia: Coverage, quality and costs now and in the future. Alzheimer's Disease International, London, UK.

[142] Atri A, Knopman DS, Norman M, Karlawish J, Sano M, Onyike CU, Lin P, Clevenger C, Scanland S, Hendrix J, Carrillo MC, Dickerson BD, Alzheimer's Association Best Clinical Practices Workgroup (2018) Details of the new Alzheimer's Association Best Clinical Practice Guidelines for the evaluation of neurodegenerative cognitive behavioral syndromes, Alzheimer's disease and dementias in the United States. Alzheimers Dement 14(7 Suppl), P1559. 